\title{
Implementação e análise de um ambiente 3D para o ensino de Geografia
}

\author{
Felipe Becker Nunes ${ }^{1}$, Gleizer Bierhalz Voss ${ }^{12}$, Fabrício Herpich ${ }^{1}$, Paulo Sindeaux ${ }^{3}$, \\ Liane Margarida Rockenbach Tarouco ${ }^{1}$, José Valdeni de Lima ${ }^{1}$ \\ ${ }^{1}$ Universidade Federal do Rio Grande do Sul (UFRGS) \\ ${ }^{2}$ Instituto Federal Farroupilha (IF Farroupilha) - Campus São Vicente do Sul \\ ${ }^{3}$ Colégio Militar de Porto Alegre \\ \{nunesfb, fabricio.herpich, gleizer.voss, paulo.sindeaux\} \\ @gmail.com, lianedpenta.ufrgs.br, valdeni@inf.ufrgs.br
}

\begin{abstract}
Resumo. Mundos virtuais permitem que sejam inseridos recursos multimidias e criados objetos $3 D$ interativos para representar experimentos e fenômenos da vida real, sendo uma instigante alternativa a ser explorada em áreas com conteúdos mais práticos. Desta forma, este artigo apresenta a criação e utilização de um mundo virtual criado no OpenSim para auxiliar no ensino de Geografia. O estudo foi aplicado com 72 participantes do ensino fundamental durante um trimestre, sendo aplicada uma análise qualitativa. Os resultados obtidos demonstraram a viabilidade da proposta e os comentários opinativos forneceram indicios positivos de que este tipo de abordagem pode ser usada de forma complementar no ensino de Geografia.
\end{abstract}

\begin{abstract}
Virtual worlds allows the insertion of multimedia resources and the creation of interactive $3 D$ objects to represent real-life experiments and phenomena, being an stimulating alternative to be explored in areas with more practical content. In this way, this article presents the creation and use of a virtual world created in OpenSim to assist teaching of Geography. The study was applied with 72 elementary students during a quarter, and a qualitative analysis was applied. The results obtained demonstrated the feasibility of the proposal and the opinionated comments provided positive indications to use this type of approach in a complementary way in the teaching of Geography.
\end{abstract}

\section{Introdução}

A área de Geografia integra o currículo escolar do Ensino Fundamental e abrange o estudo de variados tópicos de ensino, como a Geologia, Oceanografia e Climatologia. Tradicionalmente, os conteúdos são abordados de uma forma mais expositiva, em que o aluno atua essencialmente como um receptor de informações a serem memorizadas, sem haver um aspecto mais interativo, colaborativo e instigando a reflexão.

À medida que a compreensão da Geografia se torna cada vez mais crucial em nossas vidas diárias, as Tecnologias da Informação e Comunicação (TIC) precisam ser incluídas na educação geográfica (TÜZÜN et al., 2009). Assim, conteúdos fundamentais da Geografia podem ser melhores trabalhados por meio das TIC, pois com elas podem 
ser propostos desafios cognitivos, modificação e enriquecimento progressivo dos esquemas de conhecimento de modo mais significativo, uma vez que permitem o acesso à variadas formas de linguagens e diferentes pontos de vista (SALES, 2009).

Dentre as alternativas providas pelas TIC, estão os Mundos Virtuais, que são ambientes online persistentes gerados pelo computador onde as pessoas podem interagir, seja para o trabalho ou lazer, de forma comparável ao mundo real (BAINBRIDGE, 2010). Os Mundos Virtuais surgem como uma alternativa instigante a ser explorada no contexto do ensino de Geografia, em virtude de permitirem a inserção de recursos didáticos como slides e vídeos, além da construção e animação de objetos 3D para representarem simulações, que usualmente são de difícil compreensão por parte dos estudantes, podem oferecer risco em sua execução ou ter um custo elevado.

Nesse contexto, este trabalho tem o objetivo de apresentar um mundo virtual criado na plataforma OpenSim para auxiliar no processo de ensino de Geografia na série fundamental. A motivação para o desenvolvimento deste projeto consiste na escassez de iniciativas relacionadas ao uso de Mundos Virtuais nesta área, assim como está centralizada na iniciativa de um grupo de docentes da área de Geografia e pesquisadores pertencentes à área de informática na educação que buscaram efetuar esta parceria para a criação deste mundo virtual.

\section{Fundamentação Teórica}

Os Mundos Virtuais, quando aplicados no contexto educacional, possibilitam ao aluno explorar os materiais didáticos disponibilizados pelo professor, e, se tornar um agente ativo em seu processo de aprendizagem. Este tipo de abordagem tem diversas características e vantagens a serem exploradas, algumas delas listadas por Kotsilieris e Dimopoulou (2013): operação síncrona em tempo real; representação de um mundo real; persistência de dados; rede conjunta de pessoas e suporte à comunicação via chat; uso de avatares para representar indivíduos; sensação de imersão; interatividade com o uso de objetos que detém scripts; e, suporte ao uso de recursos multimídia.

Desta forma, os Mundos Virtuais podem fornecer aos alunos a prática experimental de um domínio particular do conhecimento, que pode ser realizado com laboratórios virtuais e objetos $3 \mathrm{D}$, agentes inteligentes, dentre outros fatores (HERPICH et al., 2016). Chang e Law (2008) ressaltam que o uso de simulações em Mundos Virtuais tem várias características particularmente úteis para o ensino de ciências, física, química e biologia. No contexto do ensino de Geografia, se torna importante evidenciar alguns pontos relacionados ao uso de recursos tecnológicos para a construção de ambientes simulados nesta área. Dentre as abordagens que foram identificadas, estão o uso de Mundos Virtuais, realidade aumentada e dispositivos móveis.

No que concerne ao escopo deste trabalho, foi constatado por meio da análise na literatura que há um baixo número de iniciativas envolvendo a implementação de Mundos Virtuais na área de Geografia, como pode ser visto em Jarvis (2008), Silva (2009) e Tüzün et al. (2009). Os trabalhos identificados buscaram analisar aspectos relacionados ao espaço geográfico do Mundo Virtual em comparação com o sistema convencional de Cartografia, e, como o uso de estratégias de jogos neste tipo de ambiente pode ser utilizado para auxiliar no ensino de Geografia. 
Demais iniciativas envolvendo áreas relacionadas a este trabalho, como a implementação de aplicativos utilizando recursos de Realidade Aumentada e o uso de dispositivos móveis podem ser vistos nas pesquisas de Thomaz et al. (2005), Silva et al. (2014) e Netto et al. (2016).

Os trabalhos citados envolveram tópicos como a divisão política e territorial dos países, aspectos relativos à vegetação, relevo, clima e hidrografia, cujo objetivo era demonstrar de forma mais prática e interativa as informações e locais do mundo real com recursos de realidade virtual e aumentada. $\mathrm{O}$ trabalho descrito neste artigo difere das demais pesquisas apresentadas por estar focado no ensino fundamental e utilizar a plataforma OpenSimulator, sendo implementado neste ambiente recursos como vídeos, slides, questões e simulações para auxiliar na prática docente de Geografia.

\section{Método de Pesquisa}

Este estudo foi planejado com base na abordagem estudo de caso com uma análise qualitativa, a qual teve como objetivo implementar o uso dos mundos virtuais para auxiliar no ensino de tópicos na área de Geografia, alternando o método tradicional que vinha sendo aplicado com os participantes deste projeto. $\mathrm{O}$ estudo de caso investiga fenômenos contemporâneos dentro de seu contexto de vida real, em situações em que as fronteiras entre o fenômeno e o contexto não estão claramente estabelecidas, onde se utiliza múltiplas fontes de evidência (YIN, 2010).

A análise de trabalhos relacionados e a construção do referencial teórico possibilitaram agregar novos conhecimentos para a elaboração do experimento realizado. A infraestrutura tecnológica necessária para efetuar a implementação do mundo virtual teve como base a utilização do OpenSim, por ser gratuita e open source.

Com relação ao desenvolvimento de objetos $3 \mathrm{D}$, foram utilizados softwares de modelagem gráfica, como Blender e Sketchup, assim como, foram inseridos recursos de programação por meio da linguagem OpenSimulator Scripting Language (OSSL), para efetuar os efeitos de animação. O software Singularity foi utilizado para visualização do mundo virtual pelos estudantes, pois efetua a renderização de forma integral dos objetos contidos no ambiente desenvolvido.

\subsection{Design do Estudo}

$\mathrm{O}$ experimento realizado ocorreu em um colégio militar durante todo o primeiro trimestre de 2017, que teve duração total de 4 meses (Fevereiro a Maio). O conteúdo da disciplina englobou cinco tópicos: Orientação Geográfica; Localização Geográfica; Mapas; Camadas da Terra; e, Formas de Relevo.

O experimento foi realizado com 3 turmas da sexta série do ensino fundamental matriculados na disciplina de Geografia. Cada turma contava com 29 alunos, o que contabiliza um total de 87 alunos. Entretanto, desta amostra, somente 72 responderam ao questionário aplicado ao final do experimento, sendo excluído do processo de análise um total de 15 de alunos. Todos os 72 alunos têm uma faixa etária menor de 18 anos.

Cada turma teve uma aula semanal com duração de 45 minutos no período da manhã, em que o conteúdo era exposto de forma oral pelo professor utilizando quadro negro e apresentação de slides. As atividades complementares foram caracterizadas pela 
utilização do mundo virtual durante o trimestre, a qual esteve mesclada entre quatro encontros presenciais com o professor no laboratório de informática do colégio, durante o trimestre (substituindo a aula presencial uma vez por mês), e, o acesso pelos alunos na modalidade a distância.

Em virtude de nenhum participante ter interagido com uma plataforma de mundos virtuais anteriormente, a primeira aula presencial no laboratório de informática teve um caráter de ambientação para os alunos, além de explicar a estrutura do laboratório virtual construído (a ser descrito na seção 5).

$\mathrm{O}$ acesso dos alunos no formato a distância foi plenamente opcional e de acordo com sua vontade, sendo fornecido tutoriais no formato de vídeo e texto para que pudessem se orientar no processo de instalação e configuração do visualizador. A seção subsequente apresenta informações relacionadas à forma com que foi efetuada a coleta dos dados e a análise dos resultados.

\subsection{Coleta e Análise dos Dados}

O experimento buscou averiguar a viabilidade da proposta de um Mundo Virtual para complementar o ensino na área de Geografia, ressaltando que o objetivo deste artigo está em apresentar uma análise qualitativa do experimento, expondo a opinião e avaliação dos participantes, sem adentrar no mérito de sua efetividade no quesito avaliação da aprendizagem. Em virtude da homogeneidade presente nas três turmas, em que aspectos referentes à faixa etária, planejamento igualitário das atividades para todos e nunca terem acessado anteriormente um Mundo Virtual, os autores deste trabalho optaram por efetuar a análise dos resultados tendo um grupo único de 72 participantes.

Para efetuar a coleta dos dados, ao final do experimento foi aplicado um questionário impresso contendo 10 questões de múltipla escolha e 2 questões dissertativas. Além disso, foram realizadas observações presenciais no laboratório de informática por parte dos autores deste trabalho. O questionário visou apresentar informações pertinentes sobre os recursos que foram utilizados no ambiente, se a proposta havia sido aprovada pelos alunos e demais fatores relevantes, assim como, possíveis dificuldades e benefícios identificados pelos participantes.

As questões de múltipla escolha tiveram cinco alternativas que variaram de 1 (discordo totalmente) até 5 (concordo totalmente), conforme estabelecido na escala Likert (1932). A técnica denominada Alfa de Cronbach (1951) foi aplicada com o objetivo de averiguar a confiabilidade das respostas dos participantes, sendo feita uma correlação entre os dados providos pelos respondentes.

A tabulação e análise das questões de múltipla escolha do questionário foi efetuada utilizando o método de clusterização com o software Statistica, em que foi definido o número de clusters com a aplicação da análise do diagrama de árvore, sendo adotado o método de ligação de Ward, com medida de distância Euclidiana. A análise dos dois clusters definidos foi efetuada com a aplicação do algoritmo K-Means, a fim de identificar se haviam comportamentos distintos e significativos que permitissem agrupar os entrevistados por semelhança (MALHOTRA, 2001). As duas questões dissertativas e as observações serviram para embasar a discussão dos resultados acerca da opinião dos participantes sobre a utilização do ambiente. 
VI Congresso Brasileiro de Informática na Educação (CBIE 2017)

Anais do XXVIII Simpósio Brasileiro de Informática na Educação (SBIE 2017)

\section{Laboratório Virtual de Geografia}

O processo de construção do laboratório de Geografia foi estabelecido após a análise dos trabalhos na literatura e delineamento da pesquisa apresentada neste artigo, sendo todo processo de construção acompanhado pelo professor da disciplina, para garantir a correta disposição e elaboração dos conteúdos e experimentos. Um espaço no Mundo Virtual foi construído contendo cinco tipos de salas diferentes que foram separadas por tipos de materiais didáticos, além de sua entrada conter um centro para personalização do avatar do usuário (troca de roupas e aparência).

A primeira sala do laboratório virtual contém diversos painéis disponibilizados para os alunos responderem às questões fornecidas pelo professor da disciplina. $O$ painel apresenta as questões ao aluno, que deve interpretá-las e selecionar a opção que considera correta. O feedback é fornecido automaticamente durante o questionário, e, ao final dele é apresentado seu desempenho total.

A segunda sala contém materiais no formato de slides, enquanto que a terceira sala é composta por pequenos trechos de textos. Em ambos os locais, são adicionadas texturas (imagens) separadas em cada painel, que foram geradas a partir da apresentação do professor, nos quais os alunos podem efetuar a leitura.

A quarta sala contém painéis que exibem vídeos ligados diretamente ao site do YouTube, em que o professor pode selecionar qual tipo de vídeo que gostaria que os alunos assistissem no mundo virtual. $\mathrm{Na}$ quinta sala criada no laboratório, foram inseridas todas as simulações desenvolvidas para os tópicos abordados neste experimento. A Figura 1 apresenta um exemplo de simulação sobre à Rosa dos Ventos.

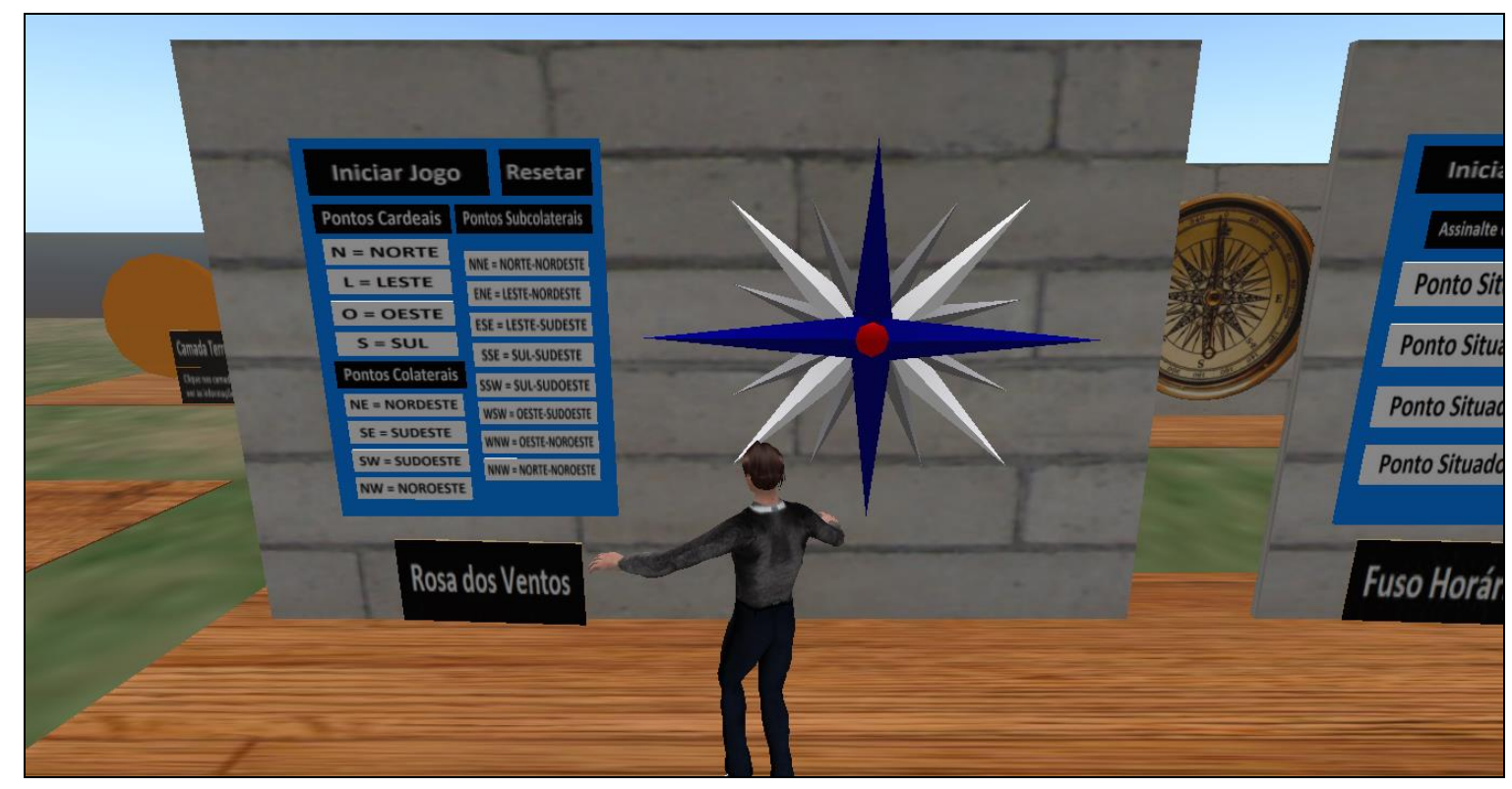

Figura 1. Simulação sobre a Rosa dos Ventos

\section{Fonte: elaborado pelos autores deste trabalho}

O formato de desafio foi adotado para esta simulação, em que os usuários iniciavam o processo visualizando uma posição na Rosa dos Ventos, de forma interativa, e, eles deveriam interpretar esta posição, assinalando qual das respostas era a correta. O feedback é fornecido imediatamente ao aluno e ele pode refazer quantas vezes 
VI Congresso Brasileiro de Informática na Educação (CBIE 2017)

Anais do XXVIII Simpósio Brasileiro de Informática na Educação (SBIE 2017)

desejar este tipo de atividade. É importante ressaltar que cada um dos cinco tópicos abordados no experimento tinha seus materiais e simulações separados e identificados em cada sala, cujo objetivo era facilitar a identificação pelo aluno do conteúdo que estava visualizando.

O Mundo Virtual foi utilizado pelos alunos durante as atividades presenciais no laboratório de informática da instituição, assim como no formato a distância, em que, aqueles que desejavam utilizar o ambiente, puderam acessar de casa. Os resultados obtidos com o experimento são analisados na seção seguinte.

\section{Análise e Discussão dos Resultados}

A técnica de Alfa de Cronbach foi aplicada para averiguar a confiabilidade das respostas dos participantes, sendo calculado o resultado final do Alfa em 0,76. Este valor pode ser considerado positivo, pois quanto mais próximo de 1, maior a confiabilidade, constatando assim que as respostas podem ser utilizadas para avaliar o ambiente.

Para efetuar o tratamento dos dados foi adotada a técnica de mineração de dados para clusterização, com o algoritmo K-Means, cujo objetivo esteve centralizado em identificar e analisar os padrões de respostas, integrando aos comentários dos participantes e observações realizadas. A Figura 2 apresenta os resultados da análise nas 10 questões objetivas, em que as respostas dos usuários foram divididas em dois clusters, para refletir diferentes padrões de respostas sobre a experiência no ambiente.

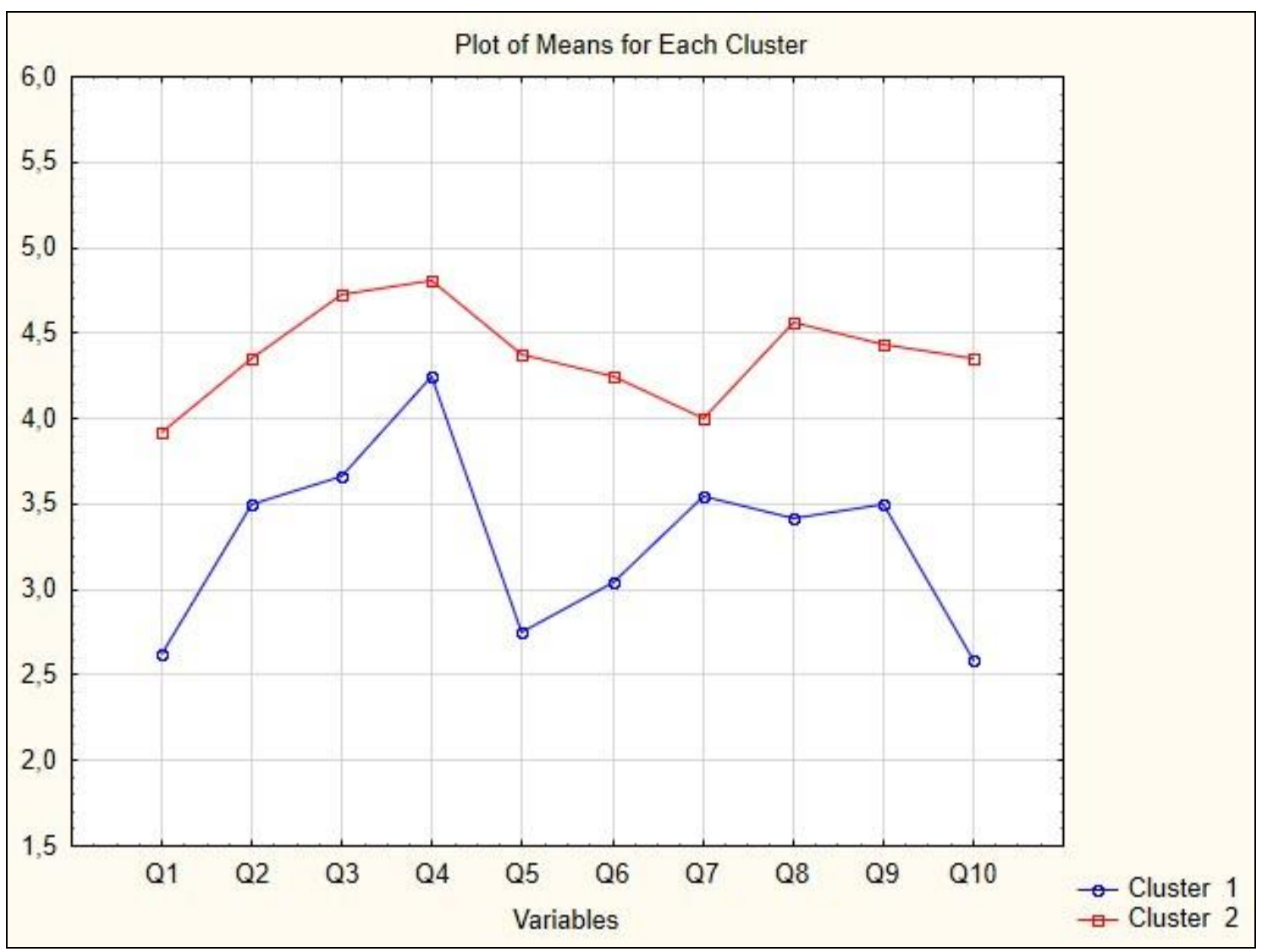

Figura 2. Padrões de resposta nos clusters analisados

Fonte: elaborado com o software Statistica pelos autores deste trabalho 
VI Congresso Brasileiro de Informática na Educação (CBIE 2017)

Anais do XXVIII Simpósio Brasileiro de Informática na Educação (SBIE 2017)

O primeiro cluster alocou 24 respostas dos usuários, sendo representado pela linha azul, enquanto que o segundo cluster alocou 48 respostas e está representado pela linha vermelha. A primeira questão buscou conhecer a opinião dos usuários sobre a viabilidade em acessar o Mundo Virtual, e, se os objetos no cenário estavam claros e consistentes. Os padrões de respostas na primeira questão estiveram aproximados de 2.5 e 4, sendo que o grupo majoritário (cluster 2) concordou positivamente com a questão, enquanto que os usuários do primeiro cluster tiveram uma impressão negativa.

Analisando os comentários e com base nas observações efetuadas durante o experimento, foi possível constatar que, uma parcela dos participantes teve dificuldades em iniciar o Mundo Virtual, assim como o cenário demorou a carregar ou foi apresentado parcialmente, devido a dificuldades na conexão de Internet. Tal fato, conforme já analisado em Fernandes et al. (2007), pode dificultar a interação do usuário e limitar seu acesso, o que justifica a baixa avaliação no cluster 1 .

A segunda questão abordou se os alunos tiveram a impressão de estarem em um cenário similar a uma sala de aula virtual, com diversas atividades didáticas. Os padrões de resposta estiveram aproximados de 3.5 e 4.5, sendo considerado positivo, visto que um dos objetivos dos idealizadores deste trabalho era construir um espaço virtual que lembrasse a ideia de um ambiente educacional, em que os alunos pudessem se sentir à vontade e bem familiarizados.

A questão 3 abordou de forma específica a utilização dos recursos de slides, vídeos e textos durante a interação no Mundo Virtual, em que os padrões de resposta ficaram aproximados de 3.5 e 5. Durante a interação, foi possível observar que os alunos estavam engajados na utilização destes recursos, buscando estudar o conteúdo com o auxílio desses no ambiente. Yilmaz et al. (2015) destacam que os recursos multimídias podem ajudar na interatividade e diversidades de opções no ambiente, ressaltando que estudantes com diferentes necessidades e preferências podem se sentir bem situados.

Com o mesmo objetivo, a quarta questão abordou especificamente sobre o uso dos questionários no Mundo Virtual para testar o conhecimento sobre o conteúdo disposto no ambiente. Os comentários dos usuários refletiram suas avaliações positivas (padrões de respostas aproximados de 4.5 e 5), sendo descrito como uma boa forma de avaliar o conhecimento e treinar o conteúdo visto. Simsek e Can (2016) destacam que proporcionando aos alunos a liberdade de escolher o tipo de material de aprendizagem a explorar, isto permite que eles criem e adaptem seu processo de aprendizagem, desenvolvendo assim uma impressão de posse desta ação e do ambiente de ensino.

No que concerne ao uso das simulações no Mundo Virtual, foram dispostos objetos retratando a Rosa dos Ventos, Escalas Cartográficas, Camadas da Terra, dentre outros tópicos. Os padrões de resposta estiveram aproximados de 3 e 4.5, sendo um aspecto considerado satisfatório, visto que se tratava de uma primeira interação com usuários neste mundo virtual. Pellas (2014) explica que essas simulações interativas proporcionam uma ilusão plausível e permite que os usuários construam situações realistas usando o ambiente $3 \mathrm{D}$ modelado. Os comentários podem ser considerados construtivos, visto que os usuários destacaram que as simulações poderiam ser mais interativas, ou seja, possibilitar que fossem adicionados valores para obter resultados e ações diferentes a cada processamento. 
A sexta questão buscou saber a opinião dos usuários sobre o tipo de ambiente utilizado, no qual podem ser manipulados avatares (representação do usuário real) e possibilita interagir com os demais colegas. Os padrões de resposta variaram entre 3 e 4.5, sendo possível notar durante o experimento que os usuários se sentiram entusiasmados em personalizar seu avatar conforme suas preferências, além de ver os colegas no ambiente em diferentes formas representativas.

Dentro deste contexto, a sétima questão abordou se os usuários achavam melhor acessar o Mundo Virtual no laboratório de informática com a presença dos colegas ao invés de estarem em casa, sendo que os padrões de respostas estiveram aproximados de 3.5 e 4, no qual os comentários acabaram mostrando uma certa divisão de opiniões entre eles. Tal constatação foi notória no momento do experimento, em que uma parcela dos usuários ficava conversando presencialmente com os colegas no laboratório sobre os recursos do ambiente, enquanto os demais eram mais introvertidos e quietos, sem aparentar terem vontade de interagir com os colegas, o que pode ser considerado normal, dada a diversidade de preferências e estilos dos alunos em uma turma.

Os padrões de resposta similares na questão oito (3.5 e 4.5) demonstram a divisão de visões na turma, a questão abordou se eles preferiam ter mais aulas presenciais no laboratório de informática ao invés de acessar somente em casa. Esta divisão mostra claramente uma diferença nos estilos de aprendizagem dos participantes e preferências diversas, o que poderia resultar em uma ação do professor mais equilibrada, mesclando entre o acesso no laboratório de informática com a turma e o estímulo para acessar de casa em horários diferentes da aula.

A nona questão buscou saber dos usuários se estes haviam aprovado este tipo de alternativa para ser utilizada na disciplina de Geografia, sendo que os padrões de respostas estiveram centralizados em 3.5 e 4.5. Tais resultados podem ser considerados satisfatórios, visto que durante a interação dos participantes no experimento foi possível notar a motivação deles em usar o ambiente e interagir com os colegas e recursos.

$\mathrm{Na}$ décima questão foi perguntado se os usuários conseguiram estudar os conteúdos abordados usando o Mundo Virtual, em que os padrões de resposta estiveram em dois extremos (2.5 e 4.5). O resultado negativo foi justificado pelos participantes como a dificuldade em acessar de casa devido a problemas na velocidade de conexão da Internet e recursos de Hardware limitados, além de alguns terem sua preferência de estudo por um método mais tradicional (anotações da aula tradicional).

\section{Considerações Finais}

A expansão do uso das TIC na área educacional proporcionou o avanço de novas iniciativas em diferentes áreas de ensino, como a Geografia. Dentre as iniciativas que vêm sendo exploradas, estão os Mundos Virtuais, que criam a possibilidade de fornecer aos usuários um espaço mais interativo e visual, fatores importantes quando considerado que esta área possui conteúdos considerados mais práticos.

A construção e experimentação de um Mundo Virtual voltado para auxiliar no ensino de Geografia pôde ser constatado no estudo descrito neste artigo, sendo que os resultados opinativos dos participantes refletiram que a abordagem foi válida, e, pode ser utilizada como um recurso complementar em disciplinas desta área no ensino 
VI Congresso Brasileiro de Informática na Educação (CBIE 2017)

Anais do XXVIII Simpósio Brasileiro de Informática na Educação (SBIE 2017)

fundamental, caracterizando seu acesso como uma atividade extra a ser desempenhada pelos alunos de forma presencial (laboratório de informática) ou a distância.

Críticas construtivas, como a melhoria das simulações e melhoramento dos desafios para haver uma maior reflexão do conteúdo, podem ser considerados essenciais para melhorar a qualidade dos recursos providos aos usuários. Como trabalhos futuros está a implementação das etapas de correção dos recursos no ambiente e a continuidade das pesquisas nesta área, sendo que o experimento continua ativo na disciplina. Uma análise quantitativa e qualitativa com avaliações da aprendizagem em diferentes turmas e instituições também se configura instigador para novas pesquisas com esta proposta.

\section{Referências}

Bainbridge, W. S. (2010). Online worlds: convergence of the real and the virtual. In Human-computer interaction series, p. 1-318.

Chang, M. K.; Law, M. S. P. (2008). Factor Structure for Young's Internet Addiction Test: a confirmatory study. In Computer in Human Behavior, v. 24, n. 6, p. 25972619.

Cronbach, L. J. (1951). Coefficient alpha and the internal structure of tests. In Psychometrika, v. 16, n. 3, p. 1-38.

Fernandes, S., Antonello, R., Moreira, J. \& Kamienski, C. (2007). Traffic Analysis Beyond This World: the Case of Second Life. In NOSSDAV'07, Urbana, Illinois USA, p. 1-7.

HERPICH, F.; NUNES, F. B.; CAZELLA, S. C.; TAROUCO, L. M. R. Mineração de Dados Educacionais: uma análise sobre o engajamento de usuários em mundos virtuais. Anais dos Workshops do $\mathrm{V}$ Congresso Brasileiro de Informática na Educação, p. 1-10, 2016.

Jarvis, C.H. (2008) Immersive visualization for learning in Geography. In Immersive Vision ${ }^{\text {ee }}$ 8, Plymouth.

Kotsilieris, T.; Dimopoulou, N. (2013). The evolution of e-learning in the context of 3D virtual worlds. In Electronic Journal of e-Learning, v. 11, n. 2, p. 147-167

Likert, R. (1932). A technique for the measurement of attitudes. In Archives of Psychology.

Malhotra, N. K. (2001). Pesquisa de marketing: uma orientação aplicada. 3. ed. Porto Alegre: Bookman, p. 1-720.

Netto, D.; Silva, G.; Melo, H.; Costa, V. (2016). Geography History: Um aplicativo para auxílio ao ensino de Geografia. In Anais do XXVII Simpósio Brasileiro de Informática na Educação, p. 1-10.

Pellas, N. (2014). The development of a virtual learning platform for teaching concurrent programming languages in secondary education: the use of open sim and scratch4os. In Journal of e-Learning and Knowledge Society, v. 10, n. 1, p. 1-15.

Sales, M. V. S. (2009). As tecnologias, o ensino e a formação do(a) professor(a) de Geografia: novas linguagens na transformação da prática. In: $10^{\circ}$ Encontro Nacional 
VI Congresso Brasileiro de Informática na Educação (CBIE 2017)

Anais do XXVIII Simpósio Brasileiro de Informática na Educação (SBIE 2017)

de Prática de Ensino em Geografia, Porto Alegre: Universidade Federal do Rio Grande do Sul, p. 1-17.

Silva, M.; Vilar, E.; Reis, G.; Lima, J. P.; Teichrieb, V. (2014). AR Jigsaw Puzzle: Potencialidades de Uso da Realidade Aumentada no Ensino de Geografia. In Anais do XXV Simpósio Brasileiro de Informática na Educação, p. 1-10.

Silva, R. C. (2009). A Geografia dos mundos virtuais: apropriação do conceito de espaço no Second Life. In XXXII Congresso Brasileiro de Ciências da Comunicação, Curitiba (PR), p. 1-13.

Simsek, I.; Can, T. (2016). The Design and Use of Educational Games in 3D Virtual Worlds. In Society for information technology and teacher education, Savannah, GA, United States, p. 611-617.

Thomaz, A. R.; Maraschin, C.; Zaniol, E.; Schuch, E. M. M. (2005). Dispositivos de imersão em ambientes de realidade virtual. In Revista brasileira de informática na educação, Florianópolis. v. 13, n. 2, p. 21-32.

Tüzün, H.; Yılmaz-Soylu, M.; Karakus, T.; Inal, Y.; Kızılkaya, G. (2009). The effects of computer games on primary school students' achievement and motivation in geography learning. In Computers \& education, v. 52, p. 68-77.

Yilmaz, R. M., Baydas, O., Karakus, T., Gokta, Y. (2015). An examination of interactions in a three-dimensional virtual world. In Computers \& Education, v. 88, p. 256-267.

Yin, R. K. (2010). Estudo de caso: planejamento e métodos. 2a Edição ed., p. 1-163. 